\title{
Design of Compact High Gain Multilayer Stacked Patch Antenna
}

\author{
NithyaDorairajan $^{\mathrm{a}, 1}$, Chitra M Perumal ${ }^{\mathrm{b}}$, PadmavathiPT $^{\mathrm{c}}$, RanjanadeviR ${ }^{\mathrm{c}}$ and \\ BhagavathShruthiVJ ${ }^{\mathrm{c}}$ \\ a Dept of ECE, Sathyabama Institute of Science and Technology, India \\ ${ }^{\mathrm{b}}$ Dept of ECE, Panimalar Institute of Technology, Chennai, India \\ ${ }^{\mathrm{c} D e p t o f}$ ECE, Panimalar Engineering College, Chennai, India
}

\begin{abstract}
In this paper a compact multilayer stacked patch antenna with high gain is proposed. The structure is composed of stacked patches with $U$ slots and shorting pins. The proposed antenna is capable for resonating at the center frequency of $2.25 \mathrm{GHz}$. The performance of the antenna is characterized by the simulated result of bandwidth, gain and reflection coefficient. The antenna has reflection coefficient of less than $-10 \mathrm{~dB}$ with a maximum gain of $7.07 \mathrm{dBi}$. The proposed antenna has bandwidth of nearly $400 \mathrm{MHz}$ and has less size with an overall height of $10.3 \mathrm{~mm}$. The designed frequency range occupies $\mathrm{S}$ band which is used for various applications like weather radar, surface ship radar, Bluetooth and ZigBee.
\end{abstract}

Keywords.antenna, multi layer, stacked patch, slot, high gain.

\section{Introduction}

Modern wireless communication systems such as cognitive radios, MIMO and 5G applications requires high bandwidth operating devices in order to provide service to the users. Broadband antenna serves this purpose and can be used in many wireless communication devices. Recently, several investigations have been focused on the design of compact wide band high gain microstrippatch antenna. Though patch antenna is light weighted and easily fabricated using photolithographic technique, narrow bandwidth is the major disadvantage in practical applications. Further trade off exists between gain and bandwidth of the patch antenna. Several gain and bandwidth enhancement or broad banding techniques has been reported in the literature, such as multilayer patches [1], coplanar directly gap-coupled patches [2], proximity coupling [3], defected ground structures [4], loading of shorting pins in the radiating patch[5] and EBG structures [6,7].

This paper focus on the design, implementation and parametric analysis of high gain multi layer stacked patch antenna with two U slots and shorting pins. Section 2 describes the design procedure of stacked patch antenna. The implementation of the proposed antenna is described in section 3. The performance of the proposed structure is described by analyzing various parameters such as gain, directivity, bandwidth, far field pattern etc. in section 4 .

\footnotetext{
${ }^{1}$ NithyaDorairajan, Deptof ECE, Panimalar Engineering College, Chennai, India. Email: shruthisrinivasan26@gmail.com.
} 


\section{Design Procedure}

The proposed antenna is designed at an operating frequency of $2.25 \mathrm{GHz}$ using Rogers RT5880 substrate with dielectric constant 2.2. The mathematical design procedure of the proposed structure is described in this section.

Step 1: Calculation of width $(W)$ of the patch

$$
W=\frac{c}{2 f_{0} \sqrt{\frac{\varepsilon_{r}+1}{2}}}=49 \mathrm{~mm}
$$

Step 2: Calculation of effective dielectric constant.

$$
\varepsilon_{\text {reff }}=\frac{\varepsilon_{r}+1}{2}+\frac{\varepsilon_{r}-1}{2}\left(1+12 \frac{h}{W}\right)^{\frac{-1}{2}}=2.1099
$$

Step 3: Calculation of effective length

$$
L_{\text {eff }}=\frac{c}{2 f_{0} \sqrt{\varepsilon_{\text {reff }}}}=43 \mathrm{~mm}
$$

Step 4: Calculation of length extension

$$
\Delta L=0.412 h \frac{\left(\varepsilon_{\text {eff }}+0.3\right)\left(\frac{W}{h}+0.264\right)}{\left(\varepsilon_{\text {eff }}-0.258\right)\left(\frac{W}{h}+0.8\right)}=0.8249 \mathrm{~mm}
$$

Step 5: Calculation of actual length of the patch

$$
L=L_{\text {eff }}-2 \Delta L=41.35 \mathrm{~mm}
$$

Step 6: Calculation of the ground length and width

$$
\begin{aligned}
& L_{g}=6 h+L=50.77 \mathrm{~mm} \\
& W_{g}=6 h+W=58.42 \mathrm{~mm}
\end{aligned}
$$


Step 7: Calculation of wavelength

$$
\lambda=\frac{c}{f_{0} \sqrt{\varepsilon_{\text {reff }}}}=86 \mathrm{~mm}
$$

\section{Step 8: Calculation of slot length}

$$
\text { Total length of the slot }=\frac{\lambda}{2}=3 \mathrm{~mm}
$$

The dimensions of the proposed structure are optimized for $50 \Omega$ impedance and are summarized in Table 1.

Table 1. Dimensions of the proposed structure

\begin{tabular}{lllllllll}
\hline Parameters & $\mathrm{W}$ & creff & Leff & $\Delta L$ & $L$ & $L g$ & $W g$ & $\lambda$ \\
\hline Values in mm & 49 & 2.1 & 43 & 0.82 & 41.35 & 50.77 & 58.42 & 86 \\
\hline
\end{tabular}

\section{Implementation}

A high gain multilayer stacked patch antenna is implemented to achieve high bandwidth. Though an antenna array can be implemented to provide high gain, a stacked patch is preferred to achieve compactness. In the proposed structure, there are two layers separated by the air gap. The bottom layer consists of ground layer, lower substrate and lower patch. The ground and lower patch is made up of copper(annealed) material which acts as the radiating metallic plates. The top layer is made up of upper substrate and upper patch. The upper patch by default is made up of copper(annealed) material. Both upper and lower substrate is employed using Rogers RT5880.

The lower patch is slotted to widen the bandwidth. The U slot is employed as it shows better performance. Two $\mathrm{U}$ slots are connected together at the lower edge to increase the current distribution. The bandwidth and efficiency are further enhanced by using shorting pins at high current density areas. Three shorting pins with same dimensions are employed at three different locations. By incorporating the parasitic patch, mutual coupling is resulted which is eliminated by increasing the distance between the patches. As the air gap increases there is an increase in the value of gain while the value of bandwidth and return loss decreases. Thus, an optimal value of the gap is employed to produce the desired results. The coaxial feeding method is employed at the lower patch. The lower patch is fed so that broadband response is obtained while feeding the upper patch provides multiband response. The upper patch is excited by the mutual coupling between both the upper patch and the lower patch. The asymmetric type of feed is employed so as to produce better polarization. (Figure. 1) shows the schematic view of top layer, bottom layer and overall structure of the proposed antenna. 


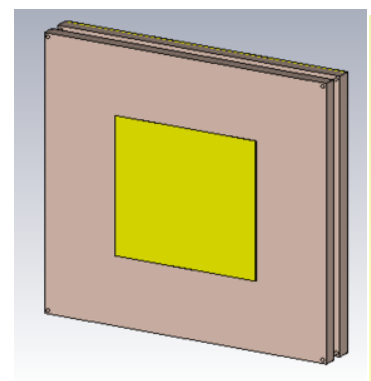

(a)

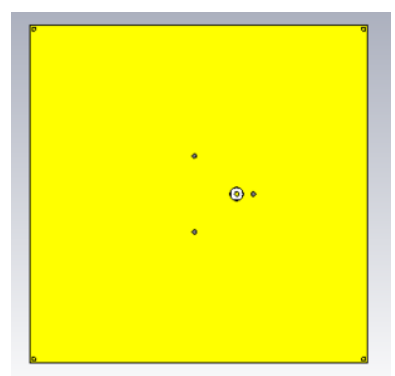

(c)

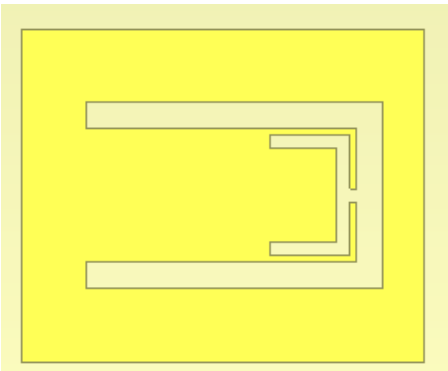

(b)

Figure 1. Schematic view of the proposed antenna (a) Overall structure (b) Top layer c) bottom layer

\section{Parametric analysis of the proposed antenna}

\subsection{S-Parameter}

The simulated $\mathrm{S}$ parameter plot in Fig. 2 shows that the antenna has operating frequency ranging from $2.06 \mathrm{GHz}$ to $2.47 \mathrm{GHz}$ with a bandwidth of nearly $400 \mathrm{MHz}$ which make it suitable for wideband applications. The reflection coefficient is less than $-10 \mathrm{~dB}$ in the entire pass band.

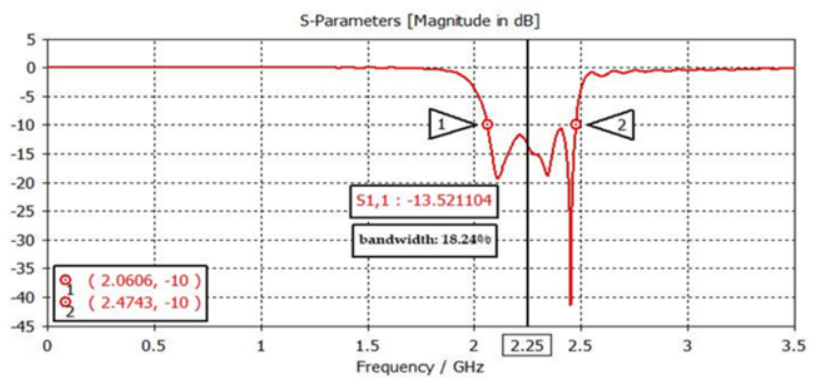

Figure 2. Reflection coefficient vs. frequency 


\subsection{Realized Gain}

The simulated realized gain vs. frequency plot in Fig.3 shows that the antenna has a maximum gain of $7.07 \mathrm{dBi}$ at the frequency of $2.25 \mathrm{GHz}$ and has the average gain of $5.27 \mathrm{dBi}$ over the entire bandwidth.

\subsection{Farfield Pattern}

(Figure 4) shows the farfield pattern with realized gain output of the proposed antenna. The antenna has maximum realized gain of $7.07 \mathrm{dBi}$. The maximum directivity achieved by the proposed antenna is $7.51 \mathrm{dBi}$.

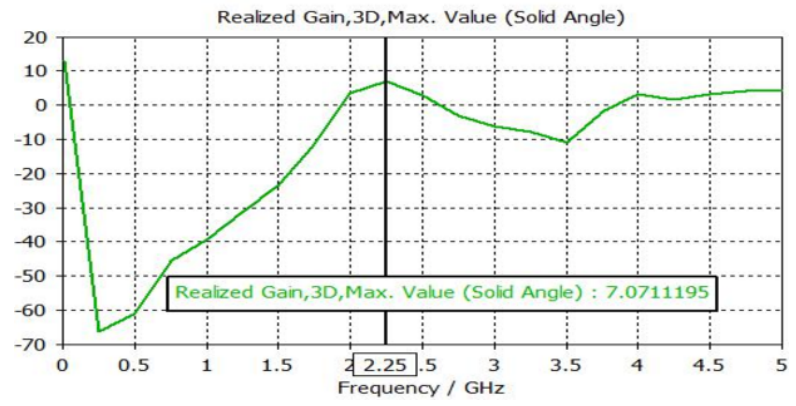

Figure 3. Realized gain vs frequency

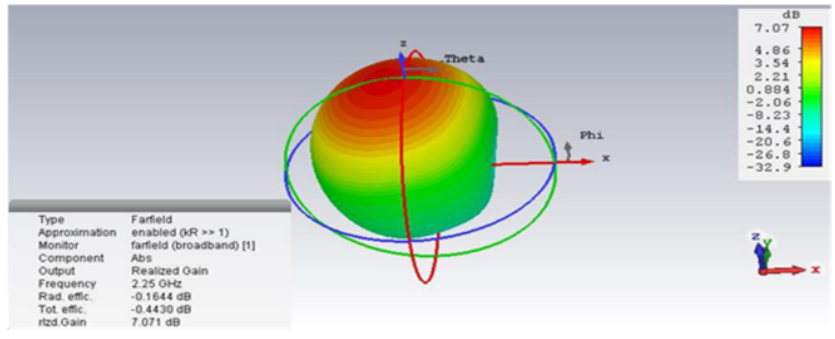

Figure 4. Far field pattern

At the frequency of $2.25 \mathrm{GHz}$, the main lobe magnitude is $4.13 \mathrm{dBW} / \mathrm{m} 2$ with the angular $3 \mathrm{~dB}$ width of $83.6^{\circ}$. It has been observed that the proposed antenna has high gain of $7.07 \mathrm{dBi}$ at $2.25 \mathrm{GHz}$ with bandwidth of nearly $400 \mathrm{MHz}$.

\subsection{E-Field Pattern and H field pattern}

The E-field pattern of the proposed antenna. At the frequency of $2.25 \mathrm{GHz}$, the main lobe magnitude is $21.6 \mathrm{dBV} / \mathrm{m} 2$ with the angular $3 \mathrm{~dB}$ width of $82.5^{\circ}$. Fig. $5 \mathrm{~b}$ shows the $\mathrm{H}$-field pattern of the proposed antenna. At the frequency of $2.25 \mathrm{GHz}$, the main lobe magnitude is $-29.9 \mathrm{dBV} / \mathrm{m} 2$ with angular $3 \mathrm{~dB}$ width of $82.5^{\circ}$.

The proposed multilayer antenna is compared with other designs in Table 2. It is shown in the table that the proposed compact antenna provides high gain and high bandwidth. 
Table 2. Comparison of the proposed structure with other designs

\begin{tabular}{|c|c|c|c|}
\hline Ref & $\begin{array}{l}\text { Impedance } \\
\text { Bandwidth }\end{array}$ & Realized gain & Size \\
\hline [1] & $17 \mathrm{MHz}$ & $6.98 \mathrm{dBi}$ & $80 \mathrm{~mm} \times 80 \mathrm{~mm} \times 8.76 \mathrm{~mm}$ \\
\hline [2] & $6.2 \%$ & $7.38 \mathrm{dBi}$ & $64 \mathrm{~mm} \times 56 \mathrm{~mm}$ \\
\hline [3] & $210 \%$ & $4 \mathrm{dBi}$ & $29.1 \mathrm{~mm} \times 29.1 \mathrm{~mm}$ \\
\hline [4] & $4.9 \%$ & $7.9 \mathrm{dBi}$ & $30 \mathrm{~mm} \times 30 \mathrm{~mm}$ \\
\hline [5] & $19.6 \%$ & $9.74 \mathrm{dBi}$ & $140 \mathrm{~mm} \times 140 \mathrm{~mm}$ \\
\hline This work & $400 \mathrm{MHz}$ & $7.07 \mathrm{dBi}$ & $80 \mathrm{~mm} \times 80 \mathrm{~mm}$ \\
\hline
\end{tabular}

\section{Conclusion}

A high gain multilayer stacked patch antenna with combined double U slots and shorting pins has been implemented for wide band applications. The antenna has reflection coefficient of less than $-10 \mathrm{~dB}$ in the entire pass band. The impedance bandwidth of $400 \mathrm{MHzand}$ directivity of $7.51 \mathrm{dBiis}$ achieved through the stacked patch. The incorporation of shorting pins away from the coaxial feed has contributed to wide bandwidth and increase in gain up to $7.07 \mathrm{dBi}$. Hence the proposed compact antenna can be used in $\mathrm{S}$ band applications such as Bluetooth, Zigbee etc.

\section{References}

[1] Wen-Chung Liu, Tzu-Yi Tang, High-gain patch antenna for cubesat-based automatic dependent surveillance-broadcast application. Microwave and Optical Technology letters, November 2018.

[2] AmalaVijaya Sri P et al.Enhancement of Gain with Coplanar Isosceles Triangular Patch Antenna for Dual-band Applications.Progress in Electromagnetics Research Symposium,2017.

[3] CitraZaskiaPratiwi and AchmadMunir.A New Method of Bandwidth Widening for Square Patch Antenna Fed by Proximity Feeding Line .Wireless and Telematics (ICWT), 2017.

[4] TahsinFerdousAraNayna, Feroz Ahmed, EmranulHaque, Bandwidth enhancement of a rectangular patch antenna in $\mathrm{X}$ band by introducing diamond shaped slot and ring in patch and defected ground structure

[5] Wireless Communications, Signal Processing and Networking, 2017.

[6] Xiu Yin Zhang, Wen Duan, and Yong-Mei Pan .High-Gain Filtering Patch Antenna without Extra Circuit”. IEEE Transactions on Antennas and Propagation, Volume: 63, Issue: 12, Dec. 2015.

[7] PongpatKetkuntod, TananHongnara, WanwisaThaiwirot, and PrayootAkkaraekthalin, "Gain Enhancement of Microstrip Patch Antenna Using I-Shaped Mushroom-like EBG Structure for WLAN Application" Antennas and Propagation (ISAP), 2017.

[8] Ramona CosminaHadarig, María Elena de Cos, Fernando Las-Heras, "Bandwidth enhancement of patch antenna using EBG/AMC structures”.Antennas and Propagation (EUCAP), 2012. 